\title{
CSF pseudocyst: an unusual cause of back pain
}

\author{
Jane Cunningham, ${ }^{1}$ David Allcutt, ${ }^{2}$ Alan O'Hare, ${ }^{3}$ Seamus Looby ${ }^{3}$
}

${ }^{1}$ Beaumont Hospital, Dublin, Ireland

${ }^{2}$ Department of Neurosurgery, Beaumont Hospital, Dublin, Ireland

${ }^{3}$ Department of Neuroradiology, Beaumont Hospital, Dublin, Ireland

\section{Correspondence to} Dr Seamus Looby, seamuslooby@hotmail.com

Accepted 3 April 2014

\section{DESCRIPTION}

A 27-year-old woman presented with a 10-month history of right-upper back pain that radiated anterolaterally along the right chest wall and was aggravated by coughing and deep inspiration. She had surgical resection of a low-grade cerebellar astrocytoma 21 years previously. Since that time, she had a ventriculoperitoneal (VP) shunt.

MRI of the cervicothoracic spinal cord failed to demonstrate any spinal abnormality to account for pain. However, there was a $15 \times 8 \mathrm{~cm}$ cystic collection in the right-upper abdominal quadrant (figure 1A, B; black star). CT of the abdomen was performed for further evaluation. Scout (figure 2A) and axial CT (figure 2B) images revealed the distal tip of the VP shunt coiled in the right subphrenic space) (arrows) and surrounded by a large simple cystic collection compressing the liver. A large amount of clear, serous fluid was drained percutaneously using ultrasound guidance. Laboratory analysis of the fluid was consistent with cerebrospinal fluid (CSF). The shunt was repositioned and her symptoms subsequently resolved.

CSFoma is a rare complication of VP shunts particularly in adults. ${ }^{1}$ A thin fibrous capsule without

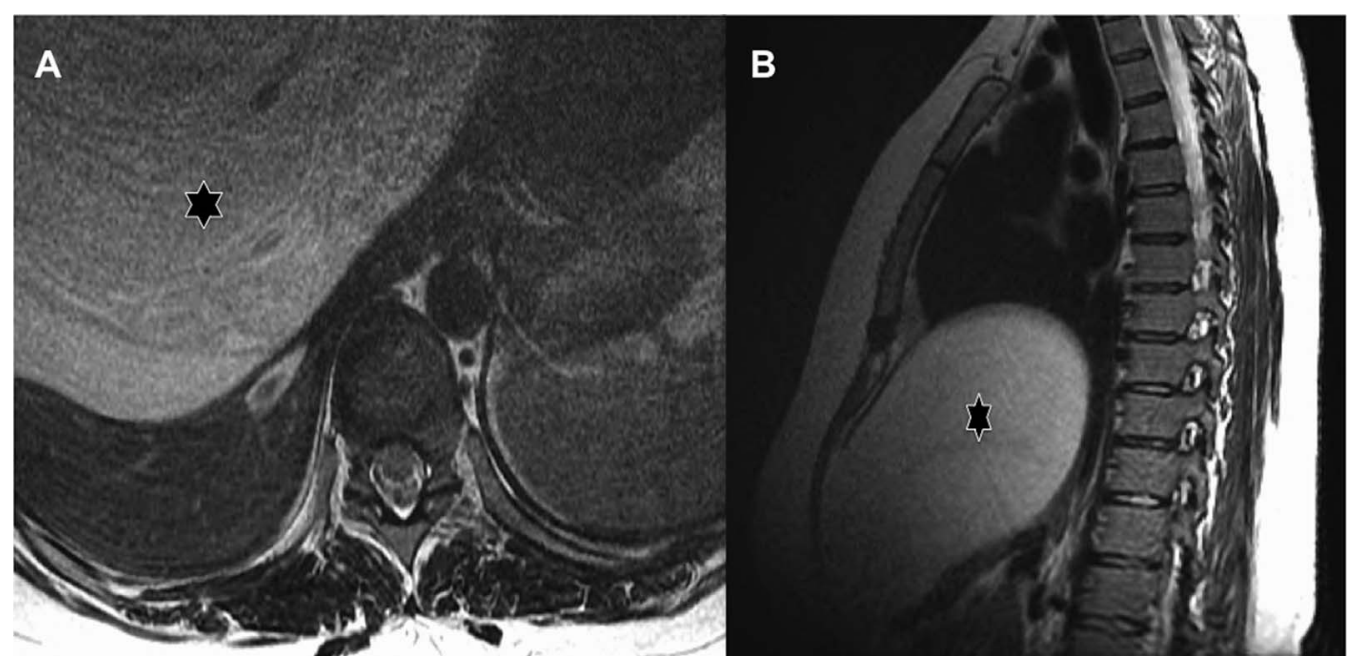

Figure 1 (A) Axial T2-weighted MRI at the level of the lower thoracic spinal cord demonstrating a very large cystic collection in the right-upper abdomen adjacent to the liver. (B) Sagittal T2-weighted MRI of the cervicothoracic spine does not show any spinal abnormality but also reveals the cystic lesion inferior to the right hemidiaphragm.

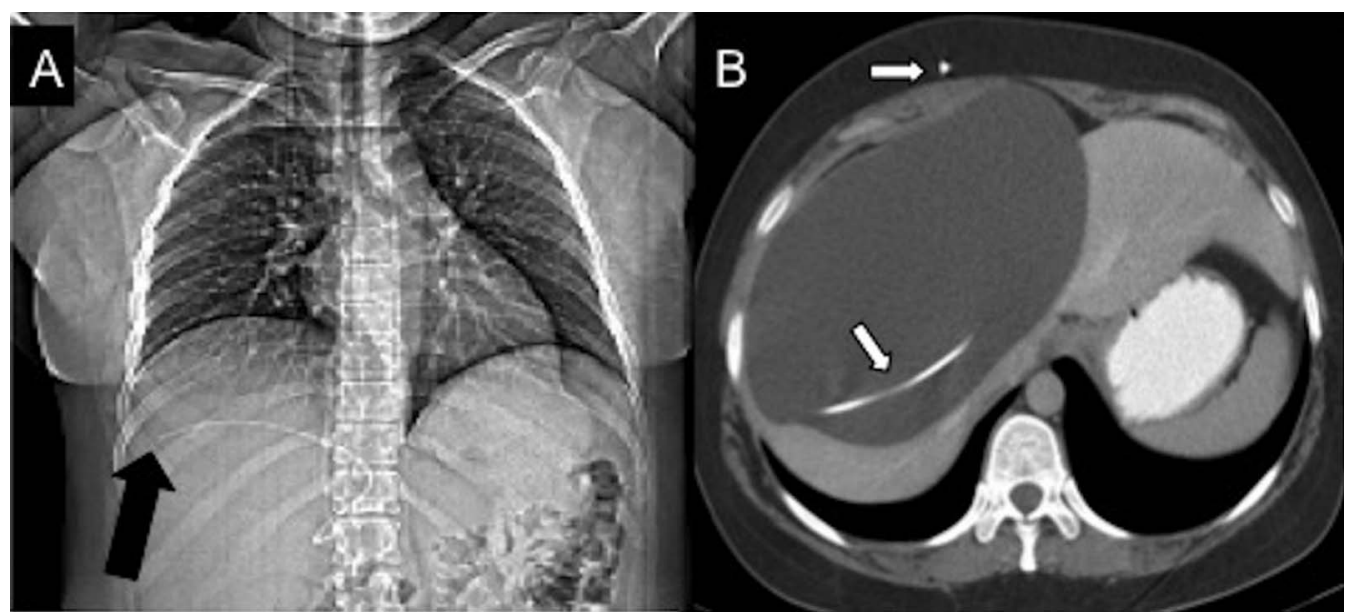

Figure 2 (A) Scout CT image revealing the tip of the ventriculoperitoneal (VP) shunt in the right-upper quadrant (black arrow). (B) Contrast-enhanced CT abdomen confirms that the VP shunt (white arrows) is coiled in the right-upper quadrant and is associated with a very large, thin-walled subphrenic collection of simple fluid $(\mathrm{HU}=10)$ consistent with a pseudocyst. 


\section{Learning points}

- This case highlights two important principles in the evaluation of radiological images:

- It is essential to examine the "edge of the film" for unexpected findings.

- It is crucial to identify and confirm satisfactory position of the tip of all catheters.

- Cerebrospinal fluid (CSF) pseudocysts are rare complications of ventriculoperitoneal shunts, which are used in the treatment of hydrocephalus and are characterised by CSF fluid collections forming at the shunt tip.

epithelial lining forms around the shunt tip and CSF accumulates within, hence the term pseudocysts. ${ }^{2}$ Low-grade shunt infection, peritoneal adhesions or chronic inflammation are the aetiological factors. ${ }^{3}$ Children typically present with symptoms of raised intracranial pressure while abdominal distension or pain predominates in adults. Shunt repositioning and percutaneous drainage or surgical excision is important in both diagnosis and management of pseudocysts.

Competing interests None.

Patient consent Obtained.

Provenance and peer review Not commissioned; externally peer reviewed.

\section{REFERENCES}

1 Dabdoub CB, Dabdoub CF, Chavez M, et al. Abdominal cerebrospinal fluid pseudocyst: a comparative analysis between children and adults. Childs Nerv Syst 2014;30:579-89.

2 Ohba S, Kinoshita Y, Tsutsui M, et al. Formation of abdominal cerebrospinal fluid pseudocyst. Neurol Med Chir 2012:52:838-42.

3 Chick JF, Chauhan NR, Mullen KM, et al. Teaching Neurolmages: massive abdominal CSFoma. Neurology 2013;80:e146.

Copyright 2014 BMJ Publishing Group. All rights reserved. For permission to reuse any of this content visit

http://group.bmj.com/group/rights-licensing/permissions.

BMJ Case Report Fellows may re-use this article for personal use and teaching without any further permission.

Become a Fellow of BMJ Case Reports today and you can:

- Submit as many cases as you like

- Enjoy fast sympathetic peer review and rapid publication of accepted articles

- Access all the published articles

Re-use any of the published material for personal use and teaching without further permission

For information on Institutional Fellowships contact consortiasales@bmjgroup.com

Visit casereports.bmj.com for more articles like this and to become a Fellow 